\title{
Reencontrar el sentido de la construcción europea
}

\section{Manifiesto del Grupo “Iniciativa de Cristianos por Europa” (Grupo IXE)}

\section{¿Qué es el Grupo IXE?}

Durante los años 90, las Semanas Sociales de Francia tomaron conciencia del hecho de que los problemas sociales ya no podían ser estudiados y debatidos más que situándolos en el contexto internacional $y$, en primer lugar, en el contexto europeo.

A fines de 1999 se iniciaron contactos y relaciones entre las Semanas Sociales de Francia y el Comité Central de los Católicos Alemanes, el ZdK. Habiendo mostrado estos intercambios que las dos organizaciones compartían profundamente las mismas preocupaciones, sus dos presidentes firmaron, en mayo siguiente, un Manifiesto para una conciencia europea, que fue el punto de partida de un proceso original.

Este proceso ha permitido la constitución progresiva de una red de " cristianos sociales » procedentes del oeste, del centro y del este de Europa, una red informal cuyo primer objetivo es hacer que sus miembros se conozcan mejor y se comprendan mejor, a pesar de la diversidad de sus sensibilidades, sus historias y sus culturas.

El segundo objetivo de esta red es constituir un lugar de observación crítica de la evolución de la construcción europea, un lugar de reflexión en referencia a los principios del pensamiento social de la Iglesia, a fin de poder expresarse y hacer propuestas en cualquier ocasión en que proceda.

En fin, esta red está llamada a movilizarse para contribuir al éxito de grandes manifestaciones de dimensión europea. Tal fue el caso, en septiembre de 2004, de la sesión del centenario de las Semanas Sociales de Francia, donde la red aseguró la presencia de un millar de participantes procedentes de países europeos distintos de Francia. Otra ocasión la constituyeron las Jornadas Católicas (Katholikentag) de Sarrebruck, en mayo de 2006, en el marco del sector temático consagrado al lugar de la justicia en la nueva Europa. Una nueva ocasión, en colaboración conjunta con la Comisión de Episcopados de la Comunidad Europea (COMECE), viene constituida actualmente por la preparación de una manifestación conmemorativa del $50^{\circ}$ aniversario del Tratado de Roma, en Roma, en marzo de 2007. 
Desde junio de 2002, esta red está animada por un Grupo de Trabajo que reúne hoy a los representantes de doce países europeos y de la Comisión de Episcopados de la Comunidad Europea (COMECE). Este Grupo está en estrecha relación con los responsables de las Semanas Sociales de España y de Italia.

Es este Grupo el que, reunido en Luxemburgo en marzo de 2006, tomó el nombre de «lniciativa de Cristianos por Europa », denominación a la que corresponden las siglas IXE.

Inmediatamente después de acabada la ampliación de la Unión Europea de 2004, que tendría que haber sido portadora de esperanza, Europa se ve hoy afrontada a la duda y al temor. Las dificultades del contexto internacional, el envejecimiento demográfico y la ascensión del individualismo y de los egoísmos nacionales debilitan esta construcción.

En el momento en que nos disponemos a conmemorar el 25 de marzo de 2007 el quincuagésimo aniversario de la firma de los Tratados que establecieron la Comunidad Económica Europea, afirmamos que la construcción europea sigue apoyada en un proyecto más amplio que acrecienta su sentido y que sigue teniendo la misma candente actualidad: la reconciliación entre los pueblos para construir un espacio de paz, de derecho, de prosperidad y de solidaridad, un espacio abierto y al servicio del mundo.

Hoy la Unión Europea debe hacer frente a nuevos retos: una globalización económica que se acelera, la pobreza que persiste o que se agrava, especialmente en África, a las puertas de la propia Europa, una inmigración masiva, conflictos en el Próximo y el Medio Oriente y amenazas graves al medio ambiente mundial. En este contexto, tanto el silencio como la indecisión de Europa resultarían culpables. Por ello es urgente poner en marcha una nueva reflexión sobre el sentido del proyecto europeo, identificar los comportamientos que tenemos que cambiar y prepararnos para asumir una responsabilidad a la altura de nuestra historia de nuestras potencialidades.

\section{I. ¿Una herencia sin proyecto?}

En vísperas del $50^{\circ}$ aniversario del Tratado de Roma, ¿̇ con qué nos encontramos ? La dinámica europea está bloqueada. La adopción del euro ha sido un éxito, pero la reunificación histórica que ha realizado la Unión Europea con la adhesión de diez - ahora ya doce - nuevos Estados miembros no se ha visto acompañada por las reformas institucionales necesarias para su buen funcionamiento, reformas que sin embargo hace ya quince años que están en marcha.

¿A qué se debe esta situación ? El proyecto europeo cuenta en ciertos países con un menor apoyo y adhesión de los ciudadanos. El desencanto de éstos con respecto a Europa que se ve reflejado en casi todas partes en la débil participación en las últimas elecciones europeas constituye la causa principal del rechazo del Tratado Constitucional por parte de dos de los Estados fundadores - Francia y Holanda - y asimismo la causa principal de la crisis actual.

Nosotros, cristianos en Europa, consideramos que ese espacio de paz, de prosperidad y de solidaridad al que apuntaba el establecimiento de la Comunidad Económica Europea en 1957 
está ya globalmente realizado, pero que la culminación de este proyecto en una verdadera Unión política sigue pendiente. Sólo una Unión así nos permitirá salir adelante en los nuevos retos a los que nos vemos afrontados. Muchos temen que la Unión se reduzca a una simple autoridad reguladora de mercados. En efecto, por ahora los gobiernos de los Estados miembros se comportan como quien vive de las rentas de esta extraordinaria herencia, pero tardan en trazar nuevas perspectivas para Europa.

Sin embargo, los pueblos siguen en busca del sentido de su convivencia. Hace cincuenta años fueron los conflictos mundiales y las amenazas del totalitarismo las que proporcionaron el imperativo de la reconciliación y unificación del continente. Hoy día los europeos han pasado a ser más ricos, pero parecen menos solidarios, al socavar el individualismo su vinculación social. Enfrentados a nuevos retos, en estos principios del siglo XXI sólo unos valores comunes y un proyecto para un adelanto de civilización podrán permitirles profundizar en su comunidad de destino y hacer frente a sus responsabilidades mundiales.

\section{Los retos de un crecimiento solidario y duradero}

De hecho, para los Estados europeos se trata de continuar siendo dueños de su destino y de aportar su contribución a la solución de los problemas de nuestro tiempo, en el concierto de las naciones. En efecto, en el momento en que las perspectivas demográficas europeas a veinte o treinta años vista son las de un indiscutible repliegue, la ascensión de nuevas potencias mundiales se realiza a velocidad vertiginosa. Está teniendo lugar un formidable reparto de cartas en la que las potencias medias corren el riesgo de perder voz y voto. La consolidación y profundización de una Unión de más de 480 millones de habitantes nos asegurarán estar a la altura de los más grandes actores mundiales y nos permitirán hacer frente más serenamente a la mundialización al convertirla en una oportunidad para todos, y especialmente para los más desfavorecidos.

Pero esto supone también que nosotros tengamos la voluntad, la imaginación y el valor de proponer un modelo de civilización más humana y de promover reglas que pongan la economía al servicio del Hombre. Los valores en los que creemos - respeto de la persona, libertad, solidaridad, democracia, justicia - nos empujan en efecto a situar al Hombre en el corazón del proyecto económico y político europeo. Es para garantizar el desarrollo humano por lo que nuestras sociedades deben buscar un crecimiento económico fuerte y sostenible, basado en el conocimiento y la innovación, en el respeto a nuestro frágil medio ambiente y a nuestros limitados recursos naturales.

El crecimiento económico es necesario para garantizar en Europa un nivel elevado de empleo y de protección social. Este crecimiento requiere hoy, lo más rápido posible, adelantos concretos, sobre todo en el establecimiento de un verdadero espacio europeo de investigación e innovación, estimulante tanto para las universidades como para la industria y dotado de un presupuesto comunitario suficiente, y requiere también la adopción de una política energética común para garantizar nuestros abastecimientos al mejor precio. 
Para hacer frente a este último problema, que es mundial, una Europa que hablara con una única voz sería un asociado e interlocutor más importante. Europa debe llegar a ser capaz de gestionar las reservas susceptibles de amortiguar conflictos en un mercado volátil, intensificar prospección e inversiones de refinado y promover energías alternativas. Así contribuirá a construir un futuro energético sostenible para todo el planeta.

Hay demasiados ciudadanos que quedan excluidos de las ventajas del crecimiento económico. Es menester que reorientemos con lucidez nuestro modo de vida individualista, dominado por el consumo. En el corazón de nuestra herencia figuran el compromiso en el proceso de garantizar la dignidad de la persona humana y la lucha contra toda forma de exclusión. Ahora bien, bajo la presión de la competencia internacional y de las evoluciones tecnológicas, y con la generalización del modelo de sociedad de consumo, Europa está hoy amenazada por la división entre quienes viven en el bienestar y la seguridad y aquellos otros, cada vez más numerosos, a los que amenaza la pobreza material y que no tienen ninguna posibilidad de alcanzar la integración social. Consiguientemente, la exigencia de justicia social llama a los estados miembros a hacer que la liberalización del mercado vaya acompañada por un refuerzo progresivo de las normas sociales, a asumir eventuales reformas de las ventajas adquiridas y a eliminar el "dumping social". Dado que la solidaridad es uno de los valores fundadores de la Unión Europea, un Tratado Constitucional debería estar convenientemente provisto de disposiciones que pusieran mejor de relieve la dimensión social, los valores y las normas que, en la diversidad de las tradiciones de los diferentes países, constituyen la herencia común. Europa debe conservar su vocación social, parte esencial de su identidad, y garantizar así a cada uno y a cada una, cualquiera que sea su origen social, el acceso a una formación, a un trabajo y a una vida decente.

Desde la preocupación por las generaciones futuras, llamamos a los dirigentes europeos a basar el crecimiento económico en fuentes renovables, a adoptar políticas presupuestarias con la mirada puesta en la preparación del porvenir y a reducir un endeudamiento que lo hipoteque.

\section{Una responsabilidad mundial}

El fenómeno de globalización de los intercambios económicos, la persistencia de los conflictos en el mundo que ha seguido a la guerra fría, las migraciones, la pobreza y las epidemias planetarias representan retos inéditos para la Unión Europea. Ellas llaman de nuevo a Europa, que conserva la riqueza de su herencia cristiana, a su responsabilidad mundial en relación con la paz, la solidaridad y la promoción de un gobierno mundial al servicio del hombre. Europa debe asumir esta responsabilidad en el mundo, y para ello debe volver a lo esencial, es decir a sus fundamentos espirituales.

Europa, por su historia reciente hecha de conflictos hoy superados y de pasos de reconciliación fructuosos, ha inventado un nuevo camino en la historia de la humanidad. Este camino hace de ella una fuente de esperanza. Este ejemplo de unión en la diversidad es un modelo que puede a su vez ayudar al mundo a progresar hacia la unidad mediante una mundialización más respetuosa de las personas. 
Europa debe ser también un modelo en lo que concierne a la convivencia de seres humanos de culturas y religiones diferentes. En un mundo globalizado, las sociedades europeas se ven invitadas cada vez más a abrirse a otras culturas y a otras religiones distintas de las propias. La Unión Europea debe tomar postura ante estas nuevas realidades, por ejemplo favoreciendo el diálogo intercultural e interreligioso, con la conciencia de que este diálogo es útil no sólo para asegurar una convivencia en paz sino también para enriquecer el propio proyecto europeo.

Todo ello implica que Europa asuma tres tareas fundamentales:

- Debe ser factor de paz y para ello debe desarrollar sus medios diplomáticos y militares en la única perspectiva que ella puede contemplar: más allá de las funciones normales de defensa, un rol mundial de prevención y de resolución de conflictos, de mantenimiento de la paz y de defensa de los derechos del hombre dondequiera que se encuentren amenazados, especialmente por los fundamentalismos y el terrorismo. Teniendo en cuenta la urgencia de este asunto, llamamos a los dirigentes europeos a construir, no desde la unanimidad ilusoria sino desde el consenso, una diplomacia europea apoyada en una defensa que la haga digna de crédito.

- Debe promover la solidaridad internacional y la colaboración para el desarrollo: Europa debe tener la preocupación primordial del respeto a la palabra dada a los países más pobres. Debe mostrarse ejemplar en la lucha por el cumplimiento de los objetivos del milenario, concentrando sus esfuerzos en la reducción de la pobreza e intensificándolos para alcanzar $-y$, lo más aprisa posible, superar - el viejo objetivo de consagrar al desarrollo el 0'7 \% del PIB.

- Debe construir una política común de inmigración basada en una aproximación radicalmente nueva al problema de las migraciones, coordinando más estrechamente políticas más humanas de acogida y de integración de los inmigrantes con políticas de desarrollo en común mucho más vigorosas en los países de emigración, en particular en el marco de la colaboración con África y con América Latina.

Más allá de estas tareas existe otra que constituye un verdadero reto para una Europa unida: imaginar, proponer y apoyar el establecimiento de un gobierno mundial al servicio del desarrollo duradero. Sólo así - con el más profundo respeto del principio de subsidiariedad- será posible abordar eficazmente problemas de dimensión mundial. En medio de las turbulencias de la mundialización, el ejemplo europeo puede ofrecer un modelo, ya se trate de sus logros constitucionales y monetarios o de la aplicación del método comunitario. Los ciudadanos europeos deben comprender que la marcha del mundo se acelera y que para Europa resulta urgente tomar en ella el lugar que le corresponde, a fin de poder asumir sin complejos las responsabilidades que corresponden a la vocación de nuestro continente. 


\section{Una unidad por profundizar}

Estamos convencidos de que Europa debe profundizar su unidad y reencontrar su coherencia. Por ello, y aun reconociendo que la perspectiva de adhesión a la Unión Europea de países candidatos es el móvil más poderoso de reforma y de reconciliación de los pueblos europeos, pensamos que el bien de los miembros actuales, igual que el de los países relacionados con ellos, requiere una pausa en las ampliaciones, a fin de que la Unión se concentre en sus reformas institucionales, lo cual no excluye el refuerzo de la cooperación con nuestros países vecinos. El aplazamiento perpetuo de estas reformas constituye una amenaza para la existencia misma de Europa. Con su lentitud en adaptarse a las nuevas realidades del mundo, Europa se está jugando su peso en la escena internacional. Resulta urgente e indispensable una reformulación de los objetivos políticos y culturales de Europa.

Más allá de las adaptaciones institucionales, esperamos de los jefes de Estado y de gobierno que definan una verdadera Ética de la gobernación europea:

- preparando las opiniones públicas para vivir en un nuevo marco institucional y para hacer suyos los envites de la Europa reunificada;

- renovando la coexistencia dinámica entre las instituciones europeas y los gobiernos nacionales para evitar el renacimiento de los soberanismos;

- volviendo a instruir en la subsidiariedad, lo que supone que los actores asuman sus responsabilidades, especialmente a nivel regional, local y de la sociedad civil.

La Unión Europea no puede construirse sin los ciudadanos. Por ello es indispensable ampliar los espacios de la ciudadanía europea, favoreciendo formas nuevas de participación cívica, estimulando la movilidad de los jóvenes mediante intercambios escolares y universitarios y organizando un amplio servicio cívico europeo.

Además, la democracia europea, que queda por construir, debe apoyarse en instituciones eficaces y en una fuerte participación ciudadana. Ahora bien, la falta de información e incluso la información errónea sobre el funcionamiento y las competencias de la Unión Europea resulta dramática. Es urgente proporcionar a los ciudadanos de Europa los medios de comprender la democracia europea y de actuar dentro de ella.

La transformación de las conciencias con respecto a Europa supone una rehabilitación de lo político y una movilización de todos los actores que pueden llevar a cabo una comunicación positiva, clara, perseverante y completa, para hacer que Europa sea percibida como más próxima y para permitir a cada una y a cada uno tomar mejor conciencia de su propia identidad europea.

Pensamos que este cambio de mentalidad no depende sólo de nuestros dirigentes políticos. A su nivel, los actores de la sociedad civil deben también tomar iniciativas, lo que les permitirá ejercer desde ahora una influencia decisiva:

Por ello lanzamos una llamada: 
- a los hombres y mujeres políticos, para que integren la dimensión europea en el corazón de sus estrategias y en sus discursos;

- a los medios de comunicación, para que destaquen la realidad de Europa, dando a conocer mejor sus diferentes países y sus diversas culturas, así como la naturaleza y el funcionamiento de las instituciones europeas;

- a los educadores, para que integren la dimensión europea en sus enseñanzas, sin esperar a una reforma de sus bases pedagógicas;

- a los diferentes actores de la vida cultural, para que, superando fronteras, multipliquen los intercambios entre naciones;

- a todos los responsables de la sociedad civil, para que inscriban sus acciones y sus realizaciones en una perspectiva europea.

Desde nuestra condición de representantes de diversos movimientos europeos de inspiración cristiana, lanzamos esta llamada a una nueva toma de conciencia por parte de todos los ciudadanos de la Unión Europea. La visión de los padres fundadores de Europa no es un asunto del pasado. Es el proyecto de futuro que espera nuestro continente, portador de esperanza para el mundo en este comienzo del siglo XXI. Es una herencia que en este momento se encuentra amenazada. Nosotros tenemos el deber de devolverle vida y transmitirla a los europeos y al mundo, y queremos trabajar por ello con todos aquellos que compartan este objetivo.

\section{Firman este manifiesto:}

Michel Camdessus Président des Semaines Sociales de France - France

Hans Joachim Meyer Président du Comité central des Catholiques allemands - Allemagne

Jean-Marie Brunot Membre du Bureau des Semaines Sociales de France - Coordinateur du Groupe IXE

Alain Heilbrunn Membre du Bureau des Semaines Sociales de France - France

Luca Jahier Présidence nationale des ACLI Secrétaire national de Retinopera - Italie

Wilhelm Rauscher Bureau du ZdK (Zentralkomitee der deutschen Katholiken)- Allemagne

María Luisa Lladó de Sols - Asociación Católica de Propagandistas - Espagne

Henryk Wo niakowski Editions ZNAK Pologne

Antoine Arjakovsky Directeur de l'Institut d'Etudes Oecuméniques Université Catholique d'Ukraine - Ukraine 
Theo Peporté Luxembourg

Anna Kolková Editions LUC - Slovaquie

Neven Simac - Cercle Académique Chrétien Croatie

Pedro Sols - Conseiller National de la ACdP (Asociación Católica de Propagandistas) - Espagne

Piotr M. A. Cywinski Président du KIK - Club de I'Intelligentsia Catholique- Pologne

Franco Garelli Secrétaire Semaines Sociales des Catholiques italiens - Italie

Peter Grubits, Secrétaire général de l'Action catholique autrichienne (KAÖ) - Autriche 